\title{
A Clinical Evaluation of Enzalutamide in Metastatic Castration-Sensitive Prostate Cancer: Guiding Principles for Treatment Selection and Perspectives on Research
}

This article was published in the following Dove Press journal:

OncoTargets and Therapy

\author{
Andrew L Laccetti (i) \\ Michael J Morris (D) \\ Philip W Kantoff \\ Genitourinary Oncology Service, \\ Department of Medicine, Memorial Sloan \\ Kettering Cancer Center, New York, \\ NY, USA
}

\begin{abstract}
Enzalutamide was the first novel androgen receptor signaling inhibitor to demonstrate an overall survival benefit in non-metastatic and metastatic castration-sensitive prostate cancer (CSPC). It has emerged as one of the most commonly prescribed oral prostate cancer therapies (ARSI) by medical oncologists and urologists. Amongst a panoply of treatment options for metastatic CSPC, safe and effective utilization of enzalutamide dictates a detailed understanding of alternative therapy options and competing toxicity profiles. Ongoing research supports the potential for expanded enzalutamide use in earlier disease states, in combination with other systemic agents and as monotherapy (without androgen deprivation therapy). Optimal application of enzalutamide will ultimately require greater insight and attention to mitigating strategies for treatment-associated fatigue, cognitive impairment, and functional decline. This publication will comprehensively analyze the clinical evidence and guiding principles of enzalutamide use in CSPC. We will also provide a critical review of ongoing and future ARSI research focusing on pharmacologic approaches to overcome treatment resistance and strategies to improve treatment-associated functional impairment.
\end{abstract}

Keywords: enzalutamide, prostate cancer, castration-sensitive, toxicity

\section{Introduction}

Metastatic castration-sensitive prostate cancer (mCSPC) was historically managed with androgen deprivation therapy (ADT); either surgical castration, gonadotropin agonists, or gonadotropin antagonists, frequently combined with firstgeneration androgen receptor (AR) antagonists (ie, bicalutamide). ${ }^{1-3}$ Despite extensive investigation of first-generation combination androgen blockade, overall survival (OS) benefit was never established with patients inevitably progressing to castration-resistant prostate cancer (CRPC), generally in 12 to 18 months. $^{2,4,5}$ Novel combination therapies have recently emerged as the standard of care with docetaxel, abiraterone acetate (AA), apalutamide, and enzalutamide all demonstrating progression-free and overall survival benefits compared to ADT alone. As a result, median OS (mOS) for mCSPC now approaches 5 years compared to less than 4 years in the pre-CHAARTED era. ${ }^{6-12}$ The therapeutic landscape of $\mathrm{mCSPC}$ offers a panoply of options for contemporary oncologists but also demands personalized treatment selection and sequencing often based on imperfect data for guidance.
Correspondence: Andrew L Laccetti Sidney Kimmel Center for Prostate and Urologic Cancers, 353 E. 68th Street Room 427, New York, NY 10065, USA

Tel + I 646-422-4683

$\mathrm{Fax}+1$ 646-227-2417

Email laccetta@mskcc.org 
Enzalutamide is a second-generation AR antagonist which, unlike first-generation antagonists, interrupts several key components of AR signaling: androgen binding to the AR, nuclear translocation of activated AR, and binding of activated AR with DNA. ${ }^{13,14}$ It was the first secondgeneration AR antagonist approved by the FDA, initially in combination with ADT for post-chemotherapy metastatic CRPC (mCRPC), then pre-chemotherapy mCRPC, non-metastatic (M0) CRPC $^{15}$ and, now, as first-line therapy in mCSPC. ${ }^{12}$ It has also emerged as the most commonly prescribed androgen receptor signaling inhibitor (ARSI: includes enzalutamide, apalutamide, and darolutamide) or androgen synthesis inhibitor (ASI: includes AA) ${ }^{16}$ favored by many prescribers aiming to avoid AA associated side effects of hepatotoxicity, mineralocorticoid excess, glucocorticoid deficiency, and steroid-induced insulin resistance in patients at risk. Enzalutamide use is limited by its own class-specific side effects including hypertension, reduced seizure threshold, fatigue, falls, and cognitive impairment. The latter three side effects are more pronounced in elderly patients, who constitute a large percentage of the prostate cancer population, and have the potential to dramatically impact quality of life (QOL) and safety. ${ }^{17-20}$

A detailed understanding of enzalutamide is essential to high-quality care of metastatic prostate cancer. This publication will comprehensively analyze the clinical evidence supporting use of enzalutamide in CSPC. We will also outline the guiding principles for treatment selection in $\mathrm{mCSPC}$ with a focus on minimizing side effect risk and preserving QOL. Finally, we will review ongoing and future ARSI and ASI research focusing on pharmacologic approaches to overcome resistance and lifestyle strategies to improve treatment-associated functional impairment.

\section{Early Development of Enzalutamide}

In an attempt to overcome molecular mechanisms of castration resistance, MDV3100 (later labeled enzalutamide) was developed as a nonsteroidal antiandrogen compound with 5- to 8-fold greater affinity for AR compared to bicalutamide and only 2 - to 3 -fold reduced affinity relative to native dihydrotestosterone. In addition to competitive antagonism, this compound was found to attenuate the efficiency of AR nuclear translocation while impairing both DNA binding to androgen response elements and recruitment of coactivators. ${ }^{13,14}$ Partial agonism or agonist-to-antagonist switch, as seen with bicalutamide, was not apparent with MDV3100, likely due to a unique structural configuration within the ligand-binding domain. $^{13,21,22}$ Additional pre-clinical studies of MDV3100 demonstrated decreased proliferation and increased death of prostate cancer cells, tumor regression in castration-resistant xenograft models ${ }^{13,22}$, and persistent in vitro activity in the setting of AR splice variants such as AR-V7/AR3, ${ }^{23}$ although this latter claim has not been clinically apparent. ${ }^{24}$

The first Phase I/II study of enzalutamide opened in July 2007 in men with mCRPC, chemotherapy refractory or naïve. Dose escalation from 30 to $600 \mathrm{mg}$ was performed establishing time to maximum concentration between $30 \mathrm{~min}$ and $4 \mathrm{~h}$, a half-life of approximately 1-week, linear pharmacokinetics, and a $240 \mathrm{mg}$ maximum tolerated dose for sustained treatment. Pre- and posttherapy FDHT-PET was performed as a marker of AR saturation by enzalutamide. Patients receiving $60 \mathrm{mg}$ per day had a smaller reduction in FDHT uptake compared to higher doses. The proportion of patients showing prostate-specific antigen (PSA) decline was dose-dependent from $30 \mathrm{mg}$ to $150 \mathrm{mg}$ per day, with no observable benefit for doses exceeding this threshold. Based on this PSA response trend, $160 \mathrm{mg}$ daily was designated for Phase III testing. Radiographic partial response was seen in $22 \%$ of patients, disease control rate was $71 \%$, and median time to PSA progression in chemotherapy-naïve patients was 41 weeks (95\% confidence interval [CI], 29-61). Dosedependent fatigue was the most common grade 3-4 adverse event and $2 \%$ of patients experienced seizure, but none below the $360 \mathrm{mg}$ per day threshold. ${ }^{25}$

It is important to recognize that the development of enzalutamide occurred in the context of mCRPC, specifically aiming to overcome resistance to ADT monotherapy. Enzalutamide demonstrates high affinity for AR, competitively overcoming well-described mechanisms of castration resistance including AR overexpression, extragonadal testosterone synthesis, and acquired sensitivity to nonandrogen ligands. Enzalutamide also inhibits AR nuclear translocation and binding with elements of transcription. The therapeutic advantage of early enzalutamide use in CSPC mechanistically remains poorly understood. One possibility is that more complete inhibition of AR signaling delays the emergence of castration resistance mechanisms. Molecular changes in response to ADT monotherapy may also prime prostate cancer cells to respond less favorably to enzalutamide in the castration-resistant setting (ie, AR splice variants, mutations in the ligand-binding 
domain, or upregulation of non-AR mediated signaling pathways). Further research addressing this topic is critical to best optimize the use of enzalutamide in CSPC and support the development of next-generation pharmacotherapies.

\section{Enzalutamide in $\mathrm{MCRPC}$}

The AFFIRM trial was the first phase III randomized study to investigate enzalutamide in MCRPC. One thousand one hundred and ninety-nine men previously exposed to docetaxel were randomized in a 2:1 fashion to enzalutamide $160 \mathrm{mg}$ daily or placebo with a primary endpoint of OS. The study was interrupted after a planned interim analysis at which time superior mOS was observed in the enzalutamide arm - 18.4 months (95\% CI, 17.3 - not reached) vs 13.6 months (95\% CI, 11.3-15.8) (hazard ratio [HR] for death in the enzalutamide group, 0.63; $\mathrm{P}<0.001)$. Enzalutamide outperformed with respect to all secondary endpoints including PSA response (at least 50\% reduction in PSA: $54 \%$ vs $2 \% ; \mathrm{P}<0.001$ ), soft tissue radiographic response rate $(29 \%$ vs $4 \% ; \mathrm{P}<0.001)$, time to the first skeletal-related event (16.7 vs 13.3 months; HR, 0.69; $\mathrm{P}<0.001$ ) and QOL (at least 10 point improvement in FACT-P: $43 \%$ vs $18 \%, \mathrm{P}<0.001) .{ }^{26}$ Similar results were later reported in a chemotherapy-naïve population with the PREVAIL trial reporting a 12-month radiographic progression-free survival (rPFS) rate of $65 \%$ compared to $9 \%$ in the placebo group ( $\mathrm{HR}, 0.19 ; \mathrm{P}<0.001)$ and an absolute reduction in the risk of death at planned interim analysis of $72 \%$ vs $63 \%(\mathrm{HR}, 0.71 ; \mathrm{P}<0.001) .{ }^{27} \mathrm{mOS}$ was later reported to favor enzalutamide with an $\mathrm{HR}$ of 0.77 $(\mathrm{P}=0.0002)$ corresponding to 35.3 months $(95 \% \mathrm{CI}$, 32.2 - not yet reached) in the enzalutamide arm and 31.3 months (95\% CI, 28.8-34.2) for placebo. As high as $29.5 \%$ of patients in the placebo arm subsequently received enzalutamide. ${ }^{28}$

The PROSPER trial was the first phase III study to report utility of an ARSI in M0 CRPC (increasing PSA level following definitive prostatectomy or radiation therapy without radiographic evidence of metastasis on conventional imaging and a testosterone level less than $50 \mathrm{ng} /$ $\mathrm{dL}$ ). One thousand four hundred and one patients with M0 CRPC and a PSA doubling time of 10 months or less were randomized to either enzalutamide $160 \mathrm{mg}$ daily or placebo (in combination with a $\mathrm{GnRH}$ agonist/antagonist). The primary endpoint of median metastasis-free survival favored enzalutamide with a corresponding HR of 0.29 $(\mathrm{P}<0.001)$ - 36.6 months (95\% CI, 33.1 - not reached) vs
14.7 months (95\% CI, 14.2-15.0). mOS was later reported at 67.0 months for the enzalutamide group (95\% CI, $64.0-$ not reached) and 56.3 months (95\% CI, 54.4-63.0) for placebo (HR, 0.73; $\mathrm{P}=0.001)^{15,29}$ Patient-reported outcomes (PROs) were superior for enzalutamide, specifically, time to pain progression (HR $0.62 ; \mathrm{p}<0.0001)$ and health-related QOL (HR for median time to deterioration in FACT-P total score; 0.62; $\mathrm{p}<0 \cdot 0001) .{ }^{29,30}$ Apalutamide and darolutamide were subsequently approved for M0 CRPC in 2018 and 2019 demonstrating similar outcomes in their respective phase III studies. ${ }^{31,32}$

\section{Combination Therapy Options for mCSPC: A Rapidly Evolving Landscape mCSPC Pre-Enzalutamide}

GnRH agonist/antagonist, surgical castration, or a firstgeneration AR antagonist (bicalutamide, flutamide, or nilutamide) was the standard of care for $\mathrm{mCSPC}$ from the late 1980s until 2015. Combination ADT and firstgeneration AR antagonists were explored in approximately 30 randomized trials conducted primarily during the 1990s. Despite sound biologic rationale, superiority of combination androgen blockade compared to ADT or AR antagonist monotherapy was never definitively established with respect to survival, safety, QOL, and costeffectiveness. $^{33}$

The landmark CHAARTED trial was the first study to establish life-prolonging potential of multiagent therapy in mCSPC reporting a 13.6-month mOS advantage with ADT plus 6 cycles of docetaxel compared to ADT alone $-\mathrm{mOS}$ 57.6 vs 44.0 months (HR 0.61; 95\%, CI 0.47-0.80; $\mathrm{P}<0.001$ ). Docetaxel's OS benefit was further supported by arm $\mathrm{C}$ of the STAMPEDE trial $^{6}$ but not GETUG-AFU 15, likely attributable to smaller sample size, lower statistical power, and a higher proportion of patients with low-volume disease. ${ }^{34}$ Across all three studies, the safety profile of docetaxel was acceptable with grade 3-4 febrile neutropenia occurring in approximately $6-15 \%$ of patients and peripheral neuropathy reported in no more than $3 \%$ of patients. ${ }^{6,7,34}$

In 2017, abiraterone acetate emerged as the first ASI to receive FDA approval in $\mathrm{mCSPC}$. The placebo-controlled, Phase 3 LATITUDE trial randomly assigned 1199 patients with high-risk $\mathrm{mCSPC}$, defined as a Gleason score of 8 or more, at least three bone lesions or presence of measurable visceral metastasis (at least 2 of 3 criteria met), to AA $1000 \mathrm{mg}$ daily with prednisone $5 \mathrm{mg}$ twice daily and 
a GnRH agonist/antagonist or GnRH agonist/antagonist alone. Markedly improved mOS was observed in the AA group - 53.3 months (95\% CI, 48.2 - not yet reached) AA arm vs 36.5 months (95\% CI, 33.5-40.0) placebo arm (HR, 0.62; $\mathrm{P}<0.001)$. mPFS was reported at almost 3 years - 33.0 months in the AA group vs 14.8 months in the placebo group (HR, 0.47; 95\% CI, 0.39-0.55; $\mathrm{P}<0.001){ }^{8}$ These findings were later confirmed by STAMPEDE arm $\mathrm{G}$ in which the AA arm demonstrated a 3-year survival rate of $83 \%$ compared to $76 \%$ in the ADT-alone group (HR, 0.63; $\mathrm{P}<0.001)$. As in the STAMPEDE arm $\mathrm{C}$ analysis (docetaxel), high risk localized and lymph node positive, non-nonmetastatic patients were included, as well. ${ }^{9}$

\section{Enzalutamide in $\mathrm{mCSPC}$}

With positive results from AFFIRM, PROSPER and PREVAIL in addition to AA showing superior outcomes when advanced to the castration-sensitive setting, the ENZAMET research collaborative conducted an international multicenter, phase III trial in which 1125 men with mCSPC were randomized to receive testosterone suppression with either enzalutamide or a standard nonsteroidal AR antagonist (bicalutamide, nilutamide, or flutamide). Early administration of docetaxel per CHAARTED, concomitant with enzalutamide or a standard nonsteroidal AR antagonist, was permitted and included as a pre-specified stratification factor. High-volume disease was present in $52 \%$ of patients and six cycles of docetaxel were administered to $65 \%$ and $76 \%$ of patients in the enzalutamide and standard of care groups, respectively. ${ }^{12}$

At the first interim analysis, ENZAMET data was unblinded to reveal superior 3-year OS for enzalutamide as estimated by the Kaplan-Meier method: $80 \%$ vs $72 \%$ (HR, 0.67; $\mathrm{P}=0.002$ ). PSA PFS and clinical PFS at 3 years for enzalutamide compared to standard of care were $67 \%$ vs $37 \%$ (HR, 0.39; $\mathrm{P}<0.001)$ and $68 \%$ vs $41 \%$ (HR, 0.40; $\mathrm{P}<0.001)$. The OS and PFS impact of enzalutamide was less among patients with planned early docetaxel (HR for OS, 0.90; $\mathrm{P}=0.04$ ) and high-volume disease (HR for OS, $0.90 ; \mathrm{P}=0.04)$. As high as $44.1 \%$ of patients in the control arm were administered enzalutamide on progression. As high as $57 \%$ and $45 \%$ of patients in the enzalutamide and standard of care arms experienced grade 3-5 adverse events with neutropenic fever (7\% and 6\%), hypertension ( $8 \%$ and $4 \%$ ), and fatigue $(6 \%$ and $1 \%$ ) reported most commonly. Seizures occurred in $1 \%$ of patients receiving enzalutamide with grade 3-5 cardiovascular adverse events occurring in $0-1 \%$ of patients in both arms. Clinically significant fatigue was reported in $25 \%$ of patients in the enzalutamide group and $14 \%$ of the standard-care arm. The frequency of serious adverse events per person-year of exposure to a trial regimen was similar in the two groups $(0.34$ vs 0.33$){ }^{12}$

ARCHES randomized 1150 men with low- and highvolume $\mathrm{mCSPC}$ to receive ADT plus enzalutamide or placebo. Participants were prospectively stratified by disease volume and prior docetaxel per CHAARTED. Unlike ENZAMET, the primary endpoint was rPFS and concurrent docetaxel was not allowed. Enzalutamide significantly reduced the risk of radiographic disease progression compared to placebo by $61 \%$ (HR, $0.39 ; \mathrm{P}<00.001)$. Time to PSA progression ( $\mathrm{HR}, 0.19 ; \mathrm{P}<0 \quad 0.001)$, next line antineoplastic therapy $(\mathrm{HR}, 0.28 ; \mathrm{P}<00.001)$ and symptomatic skeletal events (HR, 0.52; $\mathrm{P}<0$ 0.026) all favored enzalutamide and toxicity profile was similar to that reported by ENZAMET. QOL metrics were alike between treatment groups including risk of deterioration of urinary symptoms (HR, 0.88; $\mathrm{P}=0.2162$ ) and time to deterioration in QOL as assessed by FACT-P (HR, 0.96; $\mathrm{P}=0.6548) .{ }^{11}$ On December 17th, 2019, enzalutamide, in combination with a GnRH agonist/antagonist or surgical castration, was awarded FDA approval for men with mCSPC, regardless of prior docetaxel status.

\section{Apalutamide in mCSPC}

TITAN was a phase III clinical trial that randomized 1052 men with $\mathrm{mCSPC}$ to receive either apalutamide $240 \mathrm{mg}$ daily or placebo in combination with ADT. High- and lowvolume disease was included in addition to patients who had received up to 6 cycles of docetaxel per CHAARTED, accounting for $10.7 \%$ of the study cohort. The primary endpoint of rPFS or death favored the apalutamide arm with $68.2 \%$ of patients demonstrating rPFS at 24 months compared to $47.5 \%$ of the placebo group (HR, 0.48; $95 \%$ CI, 0.39-0.60; $\mathrm{P}<0.001)$. Twenty-four-month OS was superior in the apalutamide group $-82.4 \%$ vs $73.5 \%$ (HR, 0.67; 95\% CI, 0.51 to $0.89 ; \mathrm{P}<0.001$ ). Subgroup analysis demonstrated similar survival impact for patients with low- and high-volume disease (HR for death, 0.67 and 0.68 ; 95\% CI $0.34-1.32$ and $0.50-0.92$ ) while prior docetaxel use demonstrated a statistical trend toward worse survival (HR for death,1.27; 95\% CI 0.52-3.09). QOL was similar between groups - median time to FACT$\mathrm{P}$ deterioration 8.87 months (95\% CI, 4.70-11.10) in the apalutamide group and 9.23 months (95\% CI, 7.39-12.91) 
for placebo (HR 1.02; 95\% CI 0.85-1.22; $\mathrm{P}=0.85$ ). The seizure rate with apalutamide was $0.6 \%$. FDA approval for apalutamide in mCSPC was awarded in September 2019. ${ }^{10}$ For a summary of mCSPC combination systemic therapy trials please see Table 1 .

\section{Combination Therapy Selection in mCSPC}

Phase III, prospective clinical trials comparing combination therapies in CSPC have yet to be completed. Barriers to the execution of such studies are considerable, namely competing pharmaceutical industry interest and long time to completion. ARASENS is an ongoing international phase III clinical trial comparing darolutamide and darolutamide plus docetaxel in mCSPC. ${ }^{35}$ This study has completed accrual with results pending read-out.

Albeit fraught with methodologic limitations, retrospective studies have been performed comparing AA and enzalutamide with no statistically significant difference in OS seen in the castration-resistant setting. ${ }^{36-38}$ A Phase II, multicenter, randomized crossover trial comparing AA followed by enzalutamide on progression or the opposite sequence for patients with mCRPC observed superior time to second PSA progression with AA first - median 19.3 months (95\% CI, $16.0-30.5)$ vs 15.2 months (95\% CI, 11.9-19.8) (HR, 0.66; $\mathrm{P}=0.036)$. PSA response to second-line therapy occurred in $36 \%$ patients for enzalutamide and $4 \%$ for AA ( $\chi^{2}$ $\mathrm{p}<0.0001)$. There was a trend toward superior OS in the abiraterone acetate first arm but, consistent with retrospective data. However, this result did not meet statistical significance - mOS 28.8 months (95\% CI, 25.4 - not reached) for the AA first arm vs 24.7 months (95\% CI, 18.8-34.0) for the enzalutamide first arm (HR, 0.79; $\mathrm{P}=0.23){ }^{39}$ Acknowledging the statistical perils of cross-study comparison, a systematic review of docetaxel, AA, and enzalutamide mCSPC trials reported no difference in OS. ${ }^{40}$ In the absence of high-quality efficacy data to differentiate survival outcomes for docetaxel, AA, enzalutamide, and apalutamide, systemic therapy selection for CSPC is primarily informed by side effect profile and patient preference.

\section{Docetaxel vs Combination Hormonal Therapy}

Docetaxel use may be informed by metastatic volume in mCSPC. However, this relationship remains controversial. Sixty-six percent of subjects met criteria for high-volume disease in CHAARTED and this population exhibited superior mOS improvement compared to the overall trial population - 49.2 vs 32.2 months (17 month differential) for high-volume disease (HR, 0.60; 95\% CI, 0.45-0.81; $\mathrm{P}<0.001)$ and 57.6 vs 44.0 months (13.6 month differential) for the overall trial population (HR, $0.61 ; 95 \% \mathrm{CI}$, $0.47-0.80 ; \mathrm{P}<0.001){ }^{7}$ CHAARTED was not adequately powered to assess the interaction between docetaxel response and disease volume. Furthermore, a metaanalysis of front-line docetaxel trials failed to support superior overall survival for high-volume disease - highvolume HR, 0.67 (95\% CI, 0.51-0.88) vs low-volume HR, 0.80 (95\% CI, 0.49-1.32). ${ }^{41}$

Side effect profile and QOL metrics generally favor ARSIs and ASIs compared to docetaxel during the ontreatment period. Nevertheless, it is important to recognize and counsel patients on the potential for non-trivial side effects of ARSIs and ASIs that can insidiously compound over years of therapy (ie, weight gain, loss of muscle mass and bone density, metabolic syndrome, and risk for cardiac disease). Longitudinal QOL analysis of STAMPEDE arm $\mathrm{G}$ and $\mathrm{C}$ suggested a trend toward improved global QOL for AA over docetaxel. Statistical significance was achieved at 3 and 6 months but fell below the predefined clinically meaningful threshold at 1 and 2 years. ${ }^{42}$

In summary, docetaxel should be presented as a reasonable option for fit men with mCSPC who demonstrate well-preserved performance status, an absence of clinically significant pre-existing neuropathy, and a willingness to endure upfront chemo-toxicity. Contraindication to ARSIs and ASIs as well as a preference for avoiding long-term oral dosing and associated side effects of combination ADT define the rationale for candidacy, as well. Lastly, if treatment cost or access to oral medications are of concern, docetaxel may be favored. ${ }^{43}$

\section{Abiraterone Acetate vs Enzalutamide}

With most patients preferring the convenience of oral therapy and avoidance of acute chemotherapy side effects, the decision between enzalutamide and AA is frequently encountered and largely guided by competing comorbidities. AA is appropriate and well tolerated by most patients apart from those with poorly controlled diabetes, which can be exacerbated by concomitant prednisone, and hepatitis, which confounds monitoring for drug associated transaminase elevation. Relative contraindications of enzalutamide include underlying seizure disorder, poorly controlled hypertension, clinically significant fatigue, and 
Table I Combination Systemic Therapy Options for mCSPC

\begin{tabular}{|c|c|c|c|c|c|c|c|}
\hline Drug & $\begin{array}{l}\text { Approval } \\
\text { Year }\end{array}$ & $\begin{array}{l}\text { Phase III } \\
\text { Trial }\end{array}$ & Inclusion Criteria & $\begin{array}{l}\text { mPFS - } \\
\text { Months } \\
\text { (vs } \\
\text { Placebo)* }\end{array}$ & $\begin{array}{l}\text { mOS - } \\
\text { Months } \\
\text { (vs } \\
\text { Placebo)* }\end{array}$ & $\begin{array}{l}\text { Grade 3-4 } \\
\text { ADE }\end{array}$ & Notes \\
\hline \multirow[t]{3}{*}{ Docetaxel } & \multirow[t]{3}{*}{2015} & $\begin{array}{l}\text { GETUG- } \\
\text { AFU- } 15^{34}\end{array}$ & $\begin{array}{l}\text { - } \text { Radiographic } \\
\text { metastasis } \\
\text { - } \mathrm{ADT} \leq 2 \text { months }\end{array}$ & $\begin{array}{l}22.9 \\
(19.6-28 \cdot 4) \\
\text { vs I2.9 } \\
(20.5-31.9) \\
\text { HR } 0.75 \\
(0.59-0.94)\end{array}$ & $\begin{array}{l}58.9 \\
(50.8-69.1) \\
\text { vs } 54.2 \\
(42.2-\mathrm{NR}) \\
\text { HR I.0I } \\
(0.75-1.36)\end{array}$ & $\begin{array}{l}\text { Neutropenic } \\
\text { Fever- } 7 \% \\
\text { Sensory } \\
\text { Neuropathy- } \\
2 \%\end{array}$ & $\begin{array}{l}\text { - Up to } 9 \text { cycles } \\
\text { Docetaxel } \\
\text { - Relatively small trial } \\
(\mathrm{N}=39 \mathrm{I}) \\
\text { - Almost } 2 / 3 r \text { of con- } \\
\text { trol patients crossed } \\
\text { over to receive } \\
\text { docetaxel } \\
\text { - } 49 \% \text { Glass prognostic } \\
\text { score of good }\end{array}$ \\
\hline & & CHAARTED $^{7}$ & $\begin{array}{l}\text { - } \text { Radiographic } \\
\text { metastasis } \\
\text { - } \mathrm{ADT} \leq \mathrm{I} 20 \text { days }\end{array}$ & $\begin{array}{l}20.2 \text { vs } I I .7 \\
\text { HR } 0.6 I \\
(0.5 I-0.72)\end{array}$ & $\begin{array}{l}57.6 \text { vs } 44.0 \\
\text { HR } 0.61 \\
(0.47-0.80)\end{array}$ & $\begin{array}{l}\text { Neutropenic } \\
\text { Fever- } 6.2 \% \\
\text { Neuropathy- } \\
0.5 \%\end{array}$ & $\begin{array}{l}\text { - Treatment benefit } \\
\text { favored high volume } \\
\text { disease }\end{array}$ \\
\hline & & $\begin{array}{l}\text { STAMPEDE } \\
(\text { Arm C) }\end{array}$ & $\begin{array}{l}\text { Radiographic metas- } \\
\text { tasis, node positive, } \\
\text { or high-risk locally } \\
\text { advanced (T3/4, } \\
\text { Gleason } 8-10, \text { PSA } \\
\geq 40 \mathrm{ng} / \mathrm{mL}) \\
\text { ADT } \leq 12 \text { weeks }\end{array}$ & $\begin{array}{l}44.2 \\
(6.6-12.3) \\
\text { vs } 38.4 \\
(5.5-I I . I) \\
\text { HR } 0.6 I \\
(0.53-0.7 I)\end{array}$ & $\begin{array}{l}8 I .0 \text { (IQR } \\
4 I-N R) \text { vs } \\
7 I .0 \text { (IQR } \\
32-N R) \\
\text { HR I.06 } \\
(0.86-1.30)\end{array}$ & $\begin{array}{l}\text { Febrile } \\
\text { Neutropenia- } \\
15 \% \text { Sensory } \\
\text { Neuropathy- } \\
3 \%\end{array}$ & $\begin{array}{l}\text { - Included high risk } \\
\text { localized and regional } \\
\text { lymph node positive } \\
\text { prostate cancer }\end{array}$ \\
\hline \multirow[t]{2}{*}{ Abiraterone } & \multirow[t]{2}{*}{2017} & LATITUDE $^{8}$ & $\begin{array}{l}\text { - Radiographic } \\
\text { metastasis } \\
\text { - High-risk disease - } \\
\text { at least } 2 \text { of the fol- } \\
\text { lowing: Gleason } \geq 8 \text {, } \\
\geq 3 \text { bone lesions, } \\
\text { visceral metastasis } \\
\text { - ADT } \leq 12 \text { weeks }\end{array}$ & $\begin{array}{l}33.0 \\
(29.0-36.8) \\
\text { vs I4.8 } \\
(14.5-16.1) \\
\text { HR } 0.47 \\
(0.39-0.55)\end{array}$ & $\begin{array}{l}53.3(48.2- \\
N R) \text { vs } 36.5 \\
(33.5-40) \\
\text { HR } 0.62 \\
(0.5 I-0.76)\end{array}$ & $\begin{array}{l}\text { Hypertension- } \\
20 \% \\
\text { Hypokalemia- } \\
\text { II\% AST/ALT } \\
\text { Increase - } 5 \%\end{array}$ & \\
\hline & & $\begin{array}{l}\text { STAMPEDE } \\
(\text { Arm G })^{9}\end{array}$ & $\begin{array}{l}\text { Radiographic metas- } \\
\text { tasis, node positive, } \\
\text { or high-risk locally } \\
\text { advanced (two of } \\
\text { following: T3/4, } \\
\text { Gleason } 8-10 \text {, PSA } \\
\geq 40 \mathrm{ng} / \mathrm{mL} \text { ) } \\
\text { - }\end{array}$ & $\begin{array}{l}\text { mPFS not } \\
\text { met } 3 \text {-year } \\
\text { PFS }=75 \% \\
\text { vs } 45 \% \\
\text { HR } 0.29 \\
(0.25-0.34)\end{array}$ & $\begin{array}{l}\text { mOS not } \\
\text { met } 3 \text {-year } \\
\text { OS }=83 \% \\
\text { vs } 76 \% \\
\text { HR } 0.63 \\
(0.52-0.76)\end{array}$ & $\begin{array}{l}\text { Hypertension - } \\
5 \% \\
\text { Hypokalemia - } \\
\text { I\% AST/ALT } \\
\text { Increase - 7\% }\end{array}$ & $\begin{array}{l}\text { - Included high risk } \\
\text { localized and regional } \\
\text { lymph node positive } \\
\text { prostate cancer }\end{array}$ \\
\hline
\end{tabular}

(Continued) 
Table I (Continued).

\begin{tabular}{|c|c|c|c|c|c|c|c|}
\hline Drug & $\begin{array}{l}\text { Approval } \\
\text { Year }\end{array}$ & $\begin{array}{l}\text { Phase III } \\
\text { Trial }\end{array}$ & Inclusion Criteria & $\begin{array}{l}\text { mPFS - } \\
\text { Months } \\
\text { (vs } \\
\text { Placebo)* }\end{array}$ & $\begin{array}{l}\text { mOS - } \\
\text { Months } \\
\text { (vs } \\
\text { Placebo)* }\end{array}$ & $\begin{array}{l}\text { Grade 3-4 } \\
\text { ADE }\end{array}$ & Notes \\
\hline \multirow[t]{2}{*}{ Enzalutamide } & \multirow[t]{2}{*}{2019} & ENZAMET $^{12}$ & $\begin{array}{l}\text { - } \text { Radiographic } \\
\text { metastasis } \\
\text { - } A D T \leq 12 \text { weeks }\end{array}$ & $\begin{array}{l}\text { mPFS not } \\
\text { met } 3-y e a r \\
\text { PFS }=68 \% \text { vs } \\
41 \% \\
\text { HR } 0.39 \\
(0.33-0.47)\end{array}$ & $\begin{array}{l}\text { mOS not } \\
\text { met } 3-y e a r \\
\text { OS }=80 \% \text { vs } \\
72 \% \\
\text { HR } 0.67 \\
(0.52-0.86)\end{array}$ & $\begin{array}{l}\text { Febrile } \\
\text { Neutropenia - } \\
7 \% \\
\text { Hypertension - } \\
8 \% \text { Fatigue - } \\
6 \% \text { Seizure - } \\
<1 \%\end{array}$ & $\begin{array}{l}\text { - Early/concomitant } \\
\text { administration of } \\
\text { docetaxel (per } \\
\text { CHAARTED) was } \\
\text { permitted and } \\
\text { included as a pre- } \\
\text { specified stratifica- } \\
\text { tion factor } \\
\text { - Stratified by high and } \\
\text { low-volume disease } \\
\text { - OS primary endpoint } \\
\text { - First-generation AR } \\
\text { antagonist for con- } \\
\text { trol (not placebo) }\end{array}$ \\
\hline & & ARCHES ${ }^{\prime \prime}$ & $\begin{array}{l}\text { - Radiographic } \\
\text { metastasis } \\
\text { - } \mathrm{ADT} \leq 3 \text { months }\end{array}$ & $\begin{array}{l}\text { NR vs } 19.0 \\
\text { I4-month } \\
\text { PFS }=86 \% \\
\text { vs } 41 \% \\
\text { HR } 0.39 \\
(0.30-0.50)\end{array}$ & $\begin{array}{l}\text { NR vs NR } \\
\text { HR } 0.8 I \\
(0.53-1.25)\end{array}$ & $\begin{array}{l}\text { Hypertension - } \\
3 \% \text { Fatigue - } \\
2 \% \text { Cognitive } \\
\text { Impairment- } 1 \% \\
\text { Seizure - < } 1 \%\end{array}$ & $\begin{array}{l}\text { - Previous docetaxel } \\
\text { (per CHAARTED) } \\
\text { allowed } \\
\text { - Stratified by high and } \\
\text { low-volume disease } \\
\text { - rPFS primary } \\
\text { endpoint }\end{array}$ \\
\hline Apalutamide & 2019 & TITAN $^{10}$ & $\begin{array}{l}\text { - } \text { Radiographic } \\
\text { metastasis } \\
\text { - } \text { ADT } \leq 6 \text { months }\end{array}$ & $\begin{array}{l}\text { mPFS not } \\
\text { met } \\
4-\text { month } \\
\text { PFS }=68 \% \\
\text { vs } 48 \% . \\
\text { HR } 0.48 \\
(0.39-0.60)\end{array}$ & $\begin{array}{l}\text { mOS not } \\
\text { met } 24- \\
\text { month OS } \\
=82 \% \text { vs } \\
73 \% \\
\text { HR } 0.67 \\
(0.51-0.89)\end{array}$ & $\begin{array}{l}\text { Hypertension - } \\
8 \% \text { Rash - } 6 \% \\
\text { Fatigue }-2 \% \\
\text { Seizure - }<1 \%\end{array}$ & $\begin{array}{l}\text { - Previous docetaxel } \\
\text { (per CHAARTED) } \\
\text { allowed }\end{array}$ \\
\hline
\end{tabular}

Note: $* 95 \%$ confidence interval included in parenthesis unless otherwise noted.

Abbreviations: mPFS, median PFS; mOS, median OS; ADE, adverse drug events; NS, not reached; HR, hazard ratio; PSA, prostate-specific antigen; ADT, androgen deprivation therapy.

cognitive impairment. Enzalutamide should also be implemented with caution for men older than 75 years with tolerance to the drug waning with advanced age, particularly with respect to falls. ${ }^{17,19}$ Apalutamide is regarded to have a similar side effect profile to enzalutamide except for a higher incidence of skin rash. However, rigorous comparison between the two drugs has yet to be performed.

Of note, underlying history of and risk factors for seizure may be of limited consequence with respect to on enzalutamide seizure risk. The UPWARD trial prospectively evaluated enzalutamide in 366 mCRPC patients with pre-existing seizure risk: medications that lower seizure threshold or prior stroke, seizure, or brain injury. As high as $1.9 \%$ of patients experienced seizure during the first 4 months of treatment which was similar to the incidence of seizure for mCRPC patients with high seizure risk not on enzalutamide. This data suggests that enzalutamide may be considered in men with a history of or predisposing factors for seizure as long as close monitoring is ensured.

QOL as assessed by FACT-P was compared in a Phase II randomized clinical trial between AA and enzalutamide. PROs generally favored AA with a greater proportion of enzalutamide patients experiencing clinically meaningful worsening in domains of physical and functional well- 
being ( $37 \%$ vs $21 \% ; \mathrm{P}=0.013 ; 39 \%$ vs $23 \%, \mathrm{P}=0.015)$. Differences were more pronounced in patients older than 75 years $(\mathrm{P}=0.003) .{ }^{17} \mathrm{QOL}$ data from the ENZAMET trial reiterated moderate impairment in cognitive and physical function but not global QOL. Deterioration-free survival rate for fatigue was worse in the enzalutamide arm. ${ }^{44}$

Enzalutamide and apalutamide are both inducers of CYP2C19, CYP2C9, and CYP3A4. They have the potential to reduce serum concentrations of drugs metabolized by these cytochrome p450 enzymes. AA induces CYP2C8 and CYP2D6, but does not induce CYP3A4. Concomitant administration of enzalutamide and apalutamide with drugs metabolized by CYP2C19, CYP2C9, and CYP3A4 is contraindicated or dictates close monitoring (depending on the specific medication). For this reason, patients on agents metabolized by $\mathrm{CP} 3 \mathrm{~A} 4$, which spans a wide array of drug classes, may be better suited to AA rather than an ARSI.

Taken together, enzalutamide or apalutamide might be considered over AA in mCSPC patients younger than 75 years with contraindications to 17 -alpha-hydroxylase inhibition or chronic steroid use and no firm contraindication to ARSIs. As darolutamide amasses data in mCSPC, this calculus may shift anticipating attenuated impact on fatigue, cognition, physical function, and seizure risk. However, current clinical data are very limited to support this hypothesis. Optimal ARSI selection ultimately demands shared decision-making and a high degree of personalized care for all patients with CSPC.

\section{Future Applications of}

\section{Enzalutamide in CSPC: A Review of Ongoing Research}

\section{Enzalutamide in Localized Disease and} Castration-Sensitive Biochemical Relapse

Modeling trials with AA, which has phase III evidence to support rPFS benefit in high risk localized (tumor stage T3 or T4, Gleason score of 8 to 10 or a PSA level $\geq 40$ ng per milliliter) and regional lymph node-positive prostate cancer treated with ADT and radiotherapy (RT), ${ }^{9}$ ongoing clinical trials are investigating the role of enzalutamide in combination with definitive or salvage RT. Six studies are specifically targeting intermediate or high risk localized prostate cancer (NCT03196388, NCT02028988, NCT02023463, NCT02064582, NCT02446444, NCT02508636) while three studies are focusing on biochemical relapse (NCT02057939, NCT02203695, NCT03809000).

ENZARAD (NCT02446444) is an open-label, international phase III trial randomizing patients with high risk localized prostate cancer to RT in combination with enzalutamide for 24 months or a conventional non-steroidal anti-androgen (ie, bicalutamide) for 6 months. Five-year OS is the primary endpoint. ${ }^{45}$ The ongoing randomized phase II study SALV-ENZA (NCT02203695) will compare salvage RT-ADT-enzalutamide and salvage RT-ADT with a primary endpoint of freedom from PSA progression. Although not yet standard or care, there is sound biologic rationale to support the use of finite enzalutamide in the setting of definitive or salvage RT-ADT.

\section{Neoadjuvant Enzalutamide Before Prostatectomy}

ADT and chemotherapy, either as monotherapy or in combination, before radical prostatectomy are generally safe and effective with respect to reducing prostate volume and tumor burden. Unfortunately, pathologic complete response rates are low and no long-term survival benefit has been observed to date, compared to surgery alone. ${ }^{46}$ For these reasons, interest has emerged in exploring the value of ARSIs pre-prostatectomy. Two randomized, phase II studies exploring neoadjuvant enzalutamide have been published to date. McKay et al randomized 75 men with high-risk localized prostate cancer to 24-weeks of neoadjuvant AA/prednisone, enzalutamide and leuprolide (APEL) or enzalutamide and leuprolide (EL). The combined rate of pathologic complete response $(\mathrm{pCR}$ ) or minimal residual disease was $30 \%$ in the APEL arm and $16 \%$ in the EL arm. ${ }^{47}$ In contrast, a single-center study comparing 24 weeks of neoadjuvant APEL versus AA and leuprolide (AAL) observed discordant results with triplet therapy demonstrating inferior pathologic downstaging: $30 \%$ compared to $50 \%$ in the AAL group, the later including 2 patients with $\mathrm{pCR}^{48}$ Two prospective clinical trials exploring neoadjuvant enzalutamide remain to be reported (NCT03860987 and NCT02159690).

At Memorial Sloan Kettering Cancer Center, a multiarm, multi-stage randomized Phase 2 trial (METACURE) is currently underway with one cohort specifically assessing the impact of neoadjuvant apalutamide, AA, and ADT in the setting of oligometastatic prostate cancer treated with radical prostatectomy, stereotactic radiotherapy to 
oligo-metastases and salvage RT to the prostate bed (NCT03436654). ${ }^{49}$ The PROTEUS trial (NCT03767244) is an international phase III study that will compare 6 months of neoadjuvant ADT and apalutamide versus ADT and placebo designating dual primary endpoints of pCR rate and metastasis-free survival. ${ }^{50}$ This trial will be a validation of metastasis-free survival as a surrogate endpoint as shown by the ICECaP initiative. ${ }^{51}$

\section{Enzalutamide Combination Therapy}

Simultaneous inhibition of the AR and androgen biosynthesis has been postulated as a strategy to mitigate adaptive responses to ADT including nuclear to cytoplasmic AR shift, rise in tumor-associated testosterone, and augmented AR expression. Unfortunately, enzalutamide in combination with AA has yielded disappointing results in CRPC without improvement in primary ARSI/ASI resistance or OS seen. ${ }^{52-54}$ Alliance A031201 was a phase III, multi-site clinical trial randomizing men with taxane, AA, and enzalutamide naïve $\mathrm{mCRPC}$ to ADT in combination with AA and enzalutamide or enzalutamide alone. The primary endpoint of OS was similar between groups - mOS 33.6 months (95\% CI, 30.5-36.4) for AA-enzalutamide and 32.7 months (95\% CI, 29.9-35.4) for enzalutamide alone $(\mathrm{P}=0.53)$. Grade $3-5$ adverse events were significantly more common in the AA-enzalutamide arm (68.8\% vs $55.6 \%) .{ }^{53}$ No ongoing trials of combination AAenzalutamide are underway in $\mathrm{mCSPC}$. One could justify this absence in line with results of A031201. However, considering the different biology of CSPC compared to CRPC, exploration of this space may still be warranted.

The critical question of how-to best sequence or combine docetaxel and enzalutamide in CSPC remains unanswered. Combination docetaxel and enzalutamide have been investigated in first-line MCRPC with an observed PFS benefit of 6 months compared to docetaxel alone. In contrast, equivalent objective response rate and similar mOS (30.5 months [CI 95\% 24.1-36.8] vs 28.7 months [95\% CI 20.7-36.6]; HR, 1.13; P = 0.5]) were reported supporting sequenced docetaxel and enzalutamide as the standard approach in CRPC. ${ }^{55}$ In ARCHES, treatment with enzalutamide was initiated after docetaxel, while, in ENZAMET, concurrent docetaxel and enzalutamide were permitted. In ENZAMET, the addition of enzalutamide to patients with planned early docetaxel use attenuated mOS benefit compared to the overall trial population (HR, 0.90 [95\% CI, 0.62-1.31] vs 0.67 [95\% CI, 0.52-0.86]). This disparity may be explained by disease volume in that high- volume disease constituted approximately $70 \%$ of patients receiving early docetaxel. In other words, the high-volume disease, with an HR for OS at 0.80 (0.59-1.07), may have masked additional treatment effect of combination docetaxel and enzalutamide. Additionally, the impact of chemo-hormonal therapy in low-volume disease may have been diluted by the more favorable outcomes afforded by lower volume disease. To date, high-quality evidence to support combination docetaxel-enzalutamide in CSPC is lacking. Further prospective research will be critical to answering this important question.

Combination trials utilizing enzalutamide and novel, nonhormonal therapies are currently underway, primarily in the castration-resistant disease space. Concomitant use of enzalutamide and inhibitors of ALK, TGF-beta, mTOR, PARP, endoglin (CD105), EZH2, Bromodomain and ExtraTerminal motif (BET), VEGF, and PD1 are under investigation. Studies of enzalutamide in combination with established prostate cancer therapies including Radium-223, Lu PSMA-617, and sipuleucel-T have been registered, as well. Combination regimens incorporating enzalutamide and other novel therapies that show promise in the CRPC setting are likely to be further examined in $\mathrm{mCSPC}$.

\section{Enzalutamide Monotherapy}

ARSIs as monotherapy may provide a means of attenuating ADT associated hot flashes, bone density loss, and diminished libido while maintaining similar efficacy to combination therapy. $5,56,57$ With increased potency compared to bicalutamide in addition to an absence of agonist/antagonist switch, enzalutamide monotherapy could demonstrate comparable anticancer outcomes with less toxicity relative to GnRH analogues alone or in combination with ARSIs or docetaxel. The EMBARK trial (NCT02319837) is an ongoing phase III study comparing leuprolide acetate and enzalutamide versus enzalutamide monotherapy versus leuprolide acetate and placebo in the setting of biochemically recurrent CSPC with a primary endpoint of metastasis-free survival. ${ }^{58}$ Data to support this trial stems from work from Tombal and colleagues who also examined the effect of enzalutamide monotherapy in biochemically recurrent and mCSPC with single-arm, phase II data suggesting efficacy and tolerance to enzalutamide monotherapy as demonstrated by a robust PSA decline. Enzalutamide alone, however, resulted in increased levels of testosterone by over $100 \%$ with $49.3 \%, 38.8 \%$, and $20.9 \%$ of patients experiencing gynecomastia, fatigue, and nipple tenderness, respectively. ${ }^{59-61}$ 
Although enzalutamide and apalutamide monotherapies have the potential to mitigate certain toxicities of testosterone lowering agents, their ability to markedly improve QOL may be significantly limited by penetration of the blood-brain barrier. ${ }^{62}$ CNS exposure to AR antagonists is postulated to produce cognitive deficits and fatigue. ${ }^{63}$ Furthermore, negative feedback on the GnRH axis results in testosterone upregulation and increased estrogen levels (via peripheral aromatization) which eventually leads to gynecomastia and breast tenderness. ${ }^{64}$ Darolutamide, a third-generation AR antagonist, does not appear to suffer from this pharmacokinetic limitation with a distinct chemical structure that likely restricts bloodbrain barrier penetration and binding affinity for $\gamma$ aminobutyric acid type A receptors. ${ }^{62,65}$ Early safety evaluations support a possible reduction in fatigue, falls, fractures, cognitive decline, seizures, and hypertension in line with CNS exclusion. ${ }^{32,66}$ Definitive studies comparing darolutamide with other ARSIs will be critical to rigorously define differential side effect profiles and are currently underway (ARACOG -NCT04335682; DaroAct NCT04157088). For a summary of ongoing ARSI and ASI clinical trials in CSPC see Table 2.

\section{Overcoming Enzalutamide Resistance: Next-Generation AR Antagonism}

\section{Resistance Mechanisms to Enzalutamide}

AR gene/protein amplification is well described as a resistance mechanism to enzalutamide and has been reported in $20-30 \%$ of patients with CRPC and up to $50 \%$ of patients previously treated with either enzalutamide or a 17-alpha-hydroxylase inhibitor. ${ }^{67}$ Compensatory intratumoral androgen synthesis from adrenally derived androgens and cholesterol or progesterone precursors is a postulated source resistance, as well. ${ }^{68,69}$ Activating AR mutations of the ligand-binding domain ${ }^{70-72}$ and AR splice variants (AR-V) have emerged as critical means of resistance to AR antagonism. ${ }^{73,74}$ Specifically, the prognostic role of circulating AR-V7 tumor DNA in CRPC has been well established with respect to enzalutamide and abiraterone acetate resistance. ${ }^{24} \mathrm{AR}$ independent mechanisms of resistance are currently under investigation including upregulation of glucocorticoid receptor signaling, which leads to restoration of certain AR target genes, and activation of alternative neoplastic pathways such as PI3K-AKT-mTOR, HER2, NF- $\kappa B$, and RB/p53.

\section{Novel Pharmacologic Solutions to \\ Enzalutamide Resistance}

"Bipolar androgen therapy," the process of alternating between supraphysiologic levels of androgens to nearcastrate levels, has been proposed as a potential strategy to overcome AR amplification. A single-arm, phase II trial enrolling $30 \mathrm{mCRPC}$ patients refractory to enzalutamide reported a $30 \%$ PSA response rate with $51 \%$ of patients challenged with enzalutamide subsequently demonstrating PSA decline. ${ }^{75}$ Four additional phase II trials examining this approach are underway (NCT03554317, NCT02286921, NCT03516812, and NCT02090114). Preclinical studies are exploring proteolysis targeting chimeric (PROTAC) technology as a means to directly degrade AR. This technique implements a bispecific molecule consisting of a ligand to AR and a covalently linked ligand of an E3 ubiquitin ligase effectively labeling AR for proteolytic degradation. ${ }^{76}$

N-terminal domain (NTD) inhibitors demonstrate great potential to overcome AR point mutations and splice variants. ${ }^{77}$ Bypassing the ligand-binding domain, NTD inhibitors can potentially inhibit full-length AR, AR-Vs, and either ligand-dependent or ligand-independent transactivation. ${ }^{74}$ Pre-clinical models have substantiated activity in CRPC xenograft models and an enzalutamideresistant, AR-V7 positive cell lines. ${ }^{78,79}$ A Phase I trial of ralaniten acetate in patients with AA or enzalutamideresistant mCRPC (NCT02606123) was initiated in 2015. Unfortunately, it was aborted in the context of suboptimal pill compliance. ${ }^{41,80}$ Additionally, trials of alternative NTD inhibitor compounds (EPI-506 and EPI-7386) are currently underway (NCT04421222, NCT02606123).

TRC-253 and GT0918 (proxalutamide) are nextgeneration ARSIs under development to overcome resistance mutations in the ligand-binding domain. ${ }^{81}$ Galeterone (TOK-001) was found to competitively antagonize mutant and wild-type AR in addition to 17-alphahydroxylase inhibition and promotion of AR degradation. ${ }^{82}$ Unfortunately, it failed to demonstrate efficacy in AR-V mCRPC during the ARMOR3-SV trial. ${ }^{83}$ Seviteronel (INO-464), a selective inhibitor 17-alphahydroxylase and mutated AR, including T877A and F876L, also failed to demonstrate safety and efficacy in a recent phase I trial enrolling patients with $\mathrm{mCRPC}^{84}$

Clinical trials evaluating the safety and efficacy of enzalutamide in combination with dexamethasone, as a means of GR degradation (NCT02491411) and 
Table 2 Ongoing Clinical Trials Investigating ARSIs and ASIs in CSPC

\begin{tabular}{|c|c|c|c|c|c|}
\hline Disease State & Drug & $\begin{array}{l}\text { Clinicaltrials. } \\
\text { gov \# }\end{array}$ & Intervention & $\begin{array}{l}\text { Primary } \\
\text { Outcome }\end{array}$ & $\begin{array}{l}\text { Disease } \\
\text { State }\end{array}$ \\
\hline \multirow[t]{17}{*}{$\begin{array}{l}\text { Neoadjuvant (Pre- } \\
\text { RP) }\end{array}$} & \multirow[t]{14}{*}{$\begin{array}{l}\text { AA/ } \\
\text { Apa }\end{array}$} & NCT03I 24433 & Apa $(12$ wks $) \rightarrow$ RP & $\begin{array}{l}\text { - Path. } \\
\text { downstaging } \\
\text { - Biochem. } \\
\text { response }\end{array}$ & $\begin{array}{l}\text { Intermediate } \\
\text { or High Risk }\end{array}$ \\
\hline & & NCT02789878 & $\begin{array}{l}\text { ADT + Abi (3 mo }) \rightarrow \mathrm{RPADT}+\mathrm{Abi}+\mathrm{Apa}(3 \mathrm{mo}) \rightarrow \\
\mathrm{RP}\end{array}$ & $\begin{array}{l}\text { - } \mathrm{PCR} \text { or near } \\
\text { PCR }\end{array}$ & High Risk \\
\hline & & NCT02903368 & $\begin{array}{l}\mathrm{ADT}+\mathrm{Abi}(6 \mathrm{mo}) \rightarrow \mathrm{RP} \rightarrow \mathrm{Obv} v \mathrm{ADT}+\mathrm{Abi}+\mathrm{Apa} \\
(12 \mathrm{mo}) \mathrm{ADT}+\mathrm{Abi}+\mathrm{Apa}(6 \mathrm{mo}) \rightarrow \mathrm{RP} \rightarrow \mathrm{Obv} v \mathrm{~s} \\
\mathrm{ADT}+\mathrm{Abi}+\mathrm{Apa}(12 \mathrm{mo})\end{array}$ & - MRD & $\begin{array}{l}\text { Intermediate } \\
\text { or High Risk }\end{array}$ \\
\hline & & NCT02849990 & $A D T+A b i+A p a(12$ wks $) \rightarrow R P$ & - $\mathrm{pCR}$ & \\
\hline & & NCT03080II6 & $\begin{array}{l}\text { ADT + Placebo (12 wks }) \rightarrow \text { RP ADT + Apa (3 wks }) \rightarrow \\
\text { RP }\end{array}$ & - MRD & \\
\hline & & NCT034I 2396 & Apa $(24 \mathrm{wks}) \rightarrow \mathrm{RP}$ & - Adjuvant RT rate & $\begin{array}{l}\text { Intermediate } \\
\text { Risk }\end{array}$ \\
\hline & & NCT02949284 & $\begin{array}{l}\text { Apa }(3 \mathrm{mo}) \rightarrow \mathrm{RP} A D T+\mathrm{Apa}+\mathrm{AA}(3 \mathrm{mo}) \rightarrow \mathrm{RP} \mathrm{RP} \\
\text { monotherapy }\end{array}$ & - Erectile function & High Risk \\
\hline & & NCT0277039I & Apa + ADT $(4$ wks $) \rightarrow R P$ & $\begin{array}{l}\text { - DHT conc. in } \\
\text { prostate }\end{array}$ & High Risk \\
\hline & & NCT0I088529 & $\mathrm{ADT}(3 \mathrm{mo}) \rightarrow \mathrm{RP} A D T+\mathrm{AA}(3 \mathrm{mo}) \rightarrow \mathrm{RP}$ & $\begin{array}{l}\text { - Rate of T stage } \leq \\
\mathrm{pT} 2\end{array}$ & $\begin{array}{l}\text { Intermediate } \\
\text { or High Risk }\end{array}$ \\
\hline & & NCT04356430 & $\mathrm{ADT}(24 \mathrm{wks}) \rightarrow \mathrm{RP} A D T+\mathrm{AA}(24 \mathrm{wks}) \rightarrow \mathrm{RP}$ & - $\mathrm{pCR}$ & High Risk \\
\hline & & NCT02160353 & ADT + AA (126 days $) \rightarrow$ RP & $\begin{array}{l}\text { - Tumor response } \\
\text { - Biochem. } \\
\text { response } \\
\text { - Prostate vol. }\end{array}$ & High Risk \\
\hline & & NCT00924469 & $\begin{array}{l}\mathrm{ADT}+\mathrm{AA}(24 \mathrm{wks}) \rightarrow \mathrm{RPADT}(12 \mathrm{wks}) \rightarrow \mathrm{ADT}+ \\
\mathrm{AA}(12 \mathrm{wks}) \rightarrow \mathrm{RP}\end{array}$ & $\begin{array}{l}\text { - Test. conc. in } \\
\text { prostate DHT } \\
\text { conc. in prostate }\end{array}$ & $\begin{array}{l}\text { Intermediate } \\
\text { or High Risk }\end{array}$ \\
\hline & & NCT03279250 & $\begin{array}{l}\mathrm{ADT}+\mathrm{Apa}(24 \mathrm{wks}) \rightarrow \mathrm{RPADT}+\mathrm{Apa}+\mathrm{AA}(24 \mathrm{wks}) \\
\rightarrow \mathrm{RP}\end{array}$ & - Rate of $\leq \mathrm{pT} 2 \mathrm{~N} 0$ & $\begin{array}{l}\text { Intermediate } \\
\text { or High Risk }\end{array}$ \\
\hline & & NCT03436654 & $\begin{array}{l}\text { ADT + Apa }(6 \mathrm{mo}) \rightarrow \mathrm{RP} \rightarrow \mathrm{ADT}+\mathrm{Apa}(4 \mathrm{mo}) \mathrm{ADT} \\
+\mathrm{Apa}+\mathrm{AA}(24 \mathrm{wks}) \rightarrow \mathrm{RP} \rightarrow \mathrm{ADT}+\mathrm{Apa}+\mathrm{AA}(4 \\
\mathrm{mo})\end{array}$ & $\begin{array}{l}\text { - } M R D \\
\text { - } P C R\end{array}$ & $\begin{array}{l}\text { High Risk or } \\
\text { Low Volume } \\
\text { MI }\end{array}$ \\
\hline & \multirow[t]{3}{*}{ Enza } & $\begin{array}{l}\text { NCT03860987 } \\
\text { NCT02I59690 }\end{array}$ & $\begin{array}{l}A D T+E n z a+A A(6 \mathrm{mo}) \rightarrow \mathrm{RP} \\
\mathrm{ADT}+\mathrm{Enza}+\mathrm{AA}(12 \mathrm{wks}) \rightarrow \mathrm{RP}\end{array}$ & $\begin{array}{l}\text { - } \text { Disease status } \\
\text { relative to } \\
\text { PSMA-PET at } 2 \\
\text { months } \\
\text { - } \text { PCR }\end{array}$ & $\begin{array}{l}\text { Intermediate } \\
\text { or High Risk } \\
\text { (NI Allowed) } \\
\text { High Risk }\end{array}$ \\
\hline & & NCT02268I75 & $\begin{array}{l}\text { ADT + Enza + Abi }(24 \text { wks }) \rightarrow \text { RP ADT + Enza + Abi } \\
(24 \text { wks }) \rightarrow \text { RP }\end{array}$ & - $\mathrm{pCR}$ & $\begin{array}{l}\text { Intermediate } \\
\text { or High Risk }\end{array}$ \\
\hline & & NCT01946I65 & $\begin{array}{l}\text { ADT + Abi }(7 \mathrm{mo}) \rightarrow \mathrm{RPADT}+\text { Enza }+ \text { Abi }(7 \mathrm{mo}) \rightarrow \\
\mathrm{RP}\end{array}$ & - Rate of $\leq \mathrm{pT} 2 \mathrm{~N} 0$ & $\begin{array}{l}\text { Intermediate } \\
\text { or High Risk }\end{array}$ \\
\hline
\end{tabular}

(Continued) 
Table 2 (Continued).

\begin{tabular}{|c|c|c|c|c|c|}
\hline Disease State & Drug & $\begin{array}{l}\text { Clinicaltrials. } \\
\text { gov \# }\end{array}$ & Intervention & $\begin{array}{l}\text { Primary } \\
\text { Outcome }\end{array}$ & $\begin{array}{l}\text { Disease } \\
\text { State }\end{array}$ \\
\hline \multirow[t]{10}{*}{$\begin{array}{l}\text { High Risk Localized } \\
\text { (ADT + RT) }\end{array}$} & \multirow[t]{5}{*}{$\begin{array}{l}\text { AA/ } \\
\text { Apa }\end{array}$} & NCT0I7I7053 & $A D T+A b i(6 m o)+R T$ & $\begin{array}{l}\text { - I-year undetect- } \\
\text { able PSA }\end{array}$ & \\
\hline & & NCT0I02306I & $A D T+A b i(24 \mathrm{mo})+R T$ & - $\underset{\text { toxicity }}{\text { Grade }} \geq 3$ & \\
\hline & & NCT02772588 & $A D T+A b i(6 \mathrm{mo})+\mathrm{RT}$ & $\begin{array}{l}\text { - 3-year biochem- } \\
\text { ical failure rate }\end{array}$ & \\
\hline & & NCT03488810 & $A D T+N S A A(6 \mathrm{mo})+\mathrm{RT} A D T+\mathrm{NSAA}(6 \mathrm{mo})+\mathrm{RT}$ & - DFS & \\
\hline & & NCT0253I5I6 & $A D T+N S A A(30 \mathrm{mo})+$ RT ADT + Apa (30 mo) + RT & - PFS & \\
\hline & \multirow[t]{5}{*}{ Enza } & NCT02028988 & Enza $(6 \mathrm{mo})+\mathrm{RT}$ & $\begin{array}{l}\text { - PSA level after } 6 \\
\text { months }\end{array}$ & \\
\hline & & NCT02023463 & $A D T+$ Enza $(6$ or $24 \mathrm{mo})+\mathrm{RT}$ & - Acute toxicities & \\
\hline & & NCT02064582 & $A D T+$ Enza $(6 \mathrm{mo})+\mathrm{RT}$ & $\begin{array}{l}\text { - Safety and } \\
\text { Tolerability }\end{array}$ & \\
\hline & & NCT02446444 & ADT + NSAA (24 mo) + RT ADT + Enza (24 mo) + RT & - OS & \\
\hline & & NCT02508636 & $A D T+$ Enza $(24 m o)+R T$ & $\begin{array}{l}\text { - PSA CR Rate of } \\
\text { treatment- } \\
\text { related toxicity }\end{array}$ & \\
\hline \multirow{10}{*}{$\begin{array}{l}\text { Biochemical } \\
\text { Persistence/Relapse } \\
\text { (Post- } \\
\text { Prostatectomy) }\end{array}$} & \multirow{7}{*}{$\begin{array}{l}\text { AA/ } \\
\text { Apa }\end{array}$} & NCT0I780220 & $A D T+A b i(6 \mathrm{mo})+\mathrm{RT}$ & - MTD & \\
\hline & & NCT04I 34260 & ADT (24 mo) + RT ADT + Abi + Apa (24 mo) + RT & - MFS & \\
\hline & & NCT03I4I67I & $\begin{array}{l}\text { ADT + NSAA (6 mo) + RT ADT + Abi + Apa (6 mo) + } \\
\text { RT }\end{array}$ & - PSA PFS & \\
\hline & & NCT033II555 & $A D T+A p a(24 \mathrm{mo})+(\mathrm{RT} \rightarrow \mathrm{Doc} \times 6)$ & - PFS & \\
\hline & & NCT04I8I203 & $A D T+A p a(6 \mathrm{mo})+\mathrm{RT}$ & - PFS & \\
\hline & & NCT044232II & $A D T(6 \mathrm{mo})+\mathrm{RT} A D T+A p a(6 \mathrm{mo})+\mathrm{RT} \pm \mathrm{SBRT}$ & - PFS & \\
\hline & & NCT03899077 & ADT (6 mo) + RT Apa (6 mo) + RT & $\begin{array}{l}\text { - EPIC-26 sexual } \\
\text { domain score }\end{array}$ & \\
\hline & \multirow[t]{3}{*}{ Enza } & NCT02057939 & Enza $(6 \mathrm{mo})+\mathrm{RT}$ & - 2-year PFS & \\
\hline & & NCT02203695 & ADT (6 mo) + RT Enza (6 mo) + RT & - PSA PFS & \\
\hline & & NCT03809000 & ADT (24 mo) + RT ADT + Enza (24 mo) + RT & - PFS & \\
\hline $\begin{array}{l}\text { Monotherapy (M0 } \\
\text { and/or mCSPC) }\end{array}$ & $\begin{array}{l}\text { AA/ } \\
\text { Apa } \\
\text { Enza }\end{array}$ & $\begin{array}{l}\text { NCT02867020 } \\
\text { NCT02319837 }\end{array}$ & $\begin{array}{l}\text { ADT + Abi Apa Apa + Abi } \\
\text { ADT Enza ADT + Enza }\end{array}$ & $\begin{array}{l}\text { - Undetectable } \\
\text { PSA rate at } 25 \\
\text { wks } \\
\text { - } \text { MFS }\end{array}$ & \\
\hline
\end{tabular}

Abbreviations: ARSI, androgen receptor signaling inhibitor; ASI, androgen synthesis inhibitor; RP, radical prostatectomy; Apa, apalutamide; AA, abiraterone acetate; Enza, enzalutamide; NSAA, nonsteroidal antiandrogen (Ist generation); mo, month; wks, weeks; path, pathologic; Biochem, biochemical; PCR, pathologic complete response; MRD, minimal residual disease; Test, testosterone; DHT, dihydrotestosterone; vol, volume; MFS, metastasis-free survival. 
CORT125281, a direct GR antagonism (NCT03437941) are currently underway. ${ }^{74}$ Inactivation of PTEN has been reported in as many as $50 \%$ of castration-resistant tumors. This alteration leads to activation of the PI3K/AKT pathway, a well-established mechanism of AR independence and a mechanism of resistance to enzalutamide. ${ }^{74}$ Recent press release of a phase III clinical trial comparing ipatasertib, an oral, highly specific AKT inhibitor, with abiraterone acetate in PTEN mutant mCRPC met its primary endpoint of rPFS suggesting the potential for FDA approval for this medication in the near future. ${ }^{85}$

\section{Tolerance to Enzalutamide: Attention to Cognition, Physical Function and Fitness}

Physical function and fitness are prognostically important and serve as critical elements of QOL in prostate cancer. Unfortunately, therapies that inhibit androgen signaling like enzalutamide significantly impair these parameters via wellestablished side effects of fatigue, accelerated osteoporosis, sarcopenic obesity, cognitive impairment, and falls. ${ }^{20,86-90}$ Duration of ADT, ARSI, and ASI treatment also positively correlates with decline in cardiorespiratory capacity (VO2max). ${ }^{91}$ In AQUARIUS, a prospective, observational Phase IV analysis of AA and enzalutamide on PROs, AA significantly outperformed enzalutamide in the domains of cognition, fatigue, and physical function. ${ }^{20}$ These findings sound caution on the safety of enzalutamide in patients with underlying fatigue, cognitive decline and functional impairment and call for an urgent need to better understand these adverse effects in pursuit of developing mitigating strategies.

PRO data, which constitutes the bulk of our understanding of function and prostate cancer, provide discrepant yet complementary information compared with clinician interpreted and objective assessments. Thus, objective measures of cognition, physical function and fitness, including functional MRI, cardiopulmonary exercise testing (CPET), quantitative functional maneuvers and continuous wearable activity tracking, have the potential to comprehensively characterize physical impairment. Dedicated research on the impact of combination ADTs impact on cardiorespiratory fitness is limited with only one published abstract to date. This study was unable to demonstrate a clear effect of either AA or enzalutamide on cardiorespiratory fitness; marked heterogeneity of $\triangle \mathrm{VO} 2$ max was reported after 21-weeks of therapy. ${ }^{92}$ The ARACOG trial (NCT04335682) is a randomized study assigning M0 and mCRPC patients to either darolutamide or enzalutamide with a primary endpoint of maximally changed cognitive domain from baseline by 24 weeks. A subset of patients will also receive pre- and posttherapy functional MRI. DaroAct (NCT04157088) is another multicenter Phase IIb trial randomizing mCRPC patients on a GnRH agonist/antagonist to receive darolutamide or enzalutamide. The primary endpoint is the proportion of patients with slowed Timed Up and Go Test (time to stand from seated, walk 10 feet and sit down again) after 24-weeks of with short physical performance battery test and daily activity level, as measured by an accelerometry device, serving as secondary endpoints. ${ }^{93}$

DaroAct and ARACOG will provide critical information regarding the impact of enzalutamide on physical and cognitive performance. However, these studies will only superficially interrogate cardiopulmonary fitness and comprehensive physical function. Tools like CPET, strength testing and integrated digital monitoring of longitudinal physiologic parameters (activity level, blood pressure, heart rate, oxygen saturation, and step count) are well positioned to characterize ARSI toxicity on a level of detail that has yet to be realized. A granular understanding of these toxicity elements will better support the development of mitigating strategies including personalized medication selection, next-generation hormone therapy design, and lifestyle interventions such as exercise therapy. Further research into enzalutamide toxicity and interventions to combat it will be essential to optimal drug use and preservation of QOL.

\section{Conclusion}

Enzalutamide was the first second-generation ARSI to demonstrate OS benefit in metastatic and non-metastatic CSPC and has emerged as one of the most popular oral prostate cancer therapies prescribed by medical oncologists and urologists. Safe and effective utilization of this medication dictates a detailed understanding of alternative combination therapy options and their competing toxicity profiles. Ongoing research supports the potential for expanded enzalutamide use in earlier disease states, in combination with other systemic agents, and as monotherapy. Nevertheless, optimal application of enzalutamide will ultimately require greater insight and attention to mitigating strategies for treatmentassociated fatigue, cognitive impairment, and functional decline. 


\section{Disclosure}

Dr. Andrew Laccetti has no disclosures to report.

Dr. Michael Morris reports his institution received funds for conducting clinical trials from Janssen and Pfizer during the conduct of the study and from Bayer, Progenics, Corcept, and Roche/Genentech, outside the submitted work; and the following disclosures for the past 24month period: uncompensated consultant for Advanced Accelerator Applications/Novartis, Johnson \& Johnson, and Progenics. Compensated consultant for ORIC Pharmaceuticals and Curium. Institutional research contracts for clinical trials with Bayer, Endocyte, Progenics, Corcept, Roche/Genentech, and Janssen.

Dr. Philip Kantoffreports personal fees from Bavarian Nordic, Context Therapeutics, OncoCellMDX, and Progenity, investment interest in Cogent Biosciences and Mirati, scientific advisory board/consulting for SnyDevRx, and Tarveda Therapeutics (used to be Blend), and founder and investment interest in Xlink, outside the submitted work. As of May 20, 2020, Dr. Kantoff W Philip reports the following disclosures for the last 24-month period: he has investment interest in Context Therapeutics LLC, DRGT, Placon, and Seer Biosciences; he is a company board member for Context Therapeutics LLC; he is a consultant/scientific advisory board member for Bavarian Nordic Immunotherapeutics, DRGT, GE Healthcare, Janssen, OncoCellMDX, Progenity, Seer Biosciences, and Tarveda Therapeutics; and he serves on data safety monitoring boards for Genentech/Roche and Merck. The authors report no other conflicts of interest for this work.

\section{References}

1. Huggins C, Hodges CV. Studies on prostatic cancer. i. the effect of castration, of estrogen and of androgen injection on serum phosphatases in metastatic carcinoma of the prostate. Cancer Res. 1941;1 (4):293-297.

2. Leuprolide Study Group. Leuprolide versus diethylstilbestrol for metastatic prostate cancer. $N$ Engl J Med. 1984;311(20):1281-1286. doi:10.1056/NEJM198411153112004

3. Kaisary AV. Current clinical studies with a new nonsteroidal antiandrogen, casodex. Prostate. 1994;25(S1):27-33. doi:10.1002/pros.2990250709

4. Crawford ED, Eisenberger MA, McLeod DG, et al. A controlled trial of leuprolide with and without flutamide in prostatic carcinoma. $N$ Engl J Med. 1989;321(7):419-424. doi:10.1056/NEJM198908173210702

5. Boccardo F, Rubagotti A, Barichello M, et al. Bicalutamide monotherapy versus flutamide plus goserelin in prostate cancer patients: results of an italian prostate cancer project study. J Clin Oncol. 1999;17(7):2027. doi:10.1200/JCO.1999.17.7.2027

6. James ND, Sydes MR, Clarke NW, et al. Addition of docetaxel, zoledronic acid, or both to first-line long-term hormone therapy in prostate cancer (STAMPEDE): survival results from an adaptive, multiarm, multistage, platform randomised controlled trial. Lancet. 2016;387(10024):1163-1177. doi:10.1016/S0140-6736(15)01037-5
7. Sweeney CJ, Chen Y-H, Carducci M, et al. Chemohormonal therapy in metastatic hormone-sensitive prostate cancer. $N$ Engl $J$ Med. 2015;373(8):737-746. doi:10.1056/NEJMoa1503747

8. Fizazi K, Tran N, Fein L, et al. Abiraterone plus Prednisone in Metastatic, Castration-Sensitive Prostate Cancer. New England Journal of Medicine. 2017;377(4):352-360.

9. James ND, De Bono JS, Spears MR, et al. Abiraterone for prostate cancer not previously treated with hormone therapy. $N$ Engl J Med. 2017;377(4):338-351. doi:10.1056/NEJMoa1702900

10. Chi KN, Agarwal N, Bjartell A, et al. Apalutamide for metastatic, castration-sensitive prostate cancer. $N$ Engl J Med. 2019;381 (1):13-24. doi:10.1056/NEJMoa1903307

11. Armstrong AJ, Szmulewitz RZ, Petrylak DP, et al. ARCHES: a randomized, phase iii study of androgen deprivation therapy with enzalutamide or placebo in men with metastatic hormone-sensitive prostate cancer. J Clin Oncol. 2019;37(32):2974-2986. doi:10.1200/ JCO.19.00799

12. Davis ID, Martin AJ, Stockler MR, et al. Enzalutamide with standard first-line therapy in metastatic prostate cancer. $N$ Engl $\mathrm{J}$ Med. 2019;381(2):121-131. doi:10.1056/NEJMoa1903835

13. Tran C, Ouk S, Clegg NJ, et al. Development of a second-generation antiandrogen for treatment of advanced prostate cancer. Science. 2009;324(5928):787-790. doi:10.1126/science.1168175

14. Scott LJ. Enzalutamide: a review in castration-resistant prostate cancer. Drugs. 2018;78(18):1913-1924. doi:10.1007/s40265-0181029-9

15. Hussain M, Fizazi K, Saad F, et al. Enzalutamide in men with nonmetastatic, castration-resistant prostate cancer. $N$ Engl J Med. 2018;378(26):2465-2474. doi:10.1056/NEJMoa1800536

16. Caram MEV, Kaufman SR, Modi PK, et al. Adoption of abiraterone and enzalutamide by urologists. Urology. 2019;131:176-183. doi:10.1016/j.urology.2019.05.012

17. Khalaf DJ, Sunderland K, Eigl BJ, et al. Health-related quality of life for abiraterone plus prednisone versus enzalutamide in patients with metastatic castration-resistant prostate cancer: results from a phase ii randomized trial. Eur Urol. 2019;75(6):940-947. doi:10.1016/j. eururo.2018.12.015

18. Moreira RB, Debiasi M, Francini E, et al. Differential side effects profile in patients with $\mathrm{MCRPC}$ treated with abiraterone or enzalutamide: a meta-analysis of randomized controlled trials. Oncotarget. 2017;8:48.

19. Graff JN, Baciarello G, Armstrong AJ, et al. Efficacy and safety of enzalutamide in patients 75 years or older with chemotherapy-naive metastatic castration-resistant prostate cancer: results from PREVAIL. Ann Oncol. 2016;27(2):286-294. doi:10.1093/annonc/ mdv542

20. Thiery-Vuillemin A, Hvid Poulsen M, Lagneau E, et al. Impact of abiraterone acetate plus prednisone or enzalutamide on fatigue and cognition in patients with metastatic castration-resistant prostate cancer: initial results from the observational AQUARiUS study. ESMO Open. 2018;3(5):e000397. doi:10.1136/esmoopen-2018-000397

21. Culig Z, Hoffmann J, Erdel M, et al. Switch from antagonist to agonist of the androgen receptor blocker bicalutamide is associated with prostate tumour progression in a new model system. $\mathrm{Br}$ J Cancer. 1999;81(2):242-251. doi:10.1038/sj.bjc.6690684

22. Guerrero J, Alfaro IE, Gómez F, Protter AA, Bernales S. Enzalutamide, an androgen receptor signaling inhibitor, induces tumor regression in a mouse model of castration-resistant prostate cancer. Prostate. 2013;73(12):1291-1305. doi:10.1002/pros.22674

23. Watson PA, Chen YF, Balbas MD, et al. Constitutively active androgen receptor splice variants expressed in castration-resistant prostate cancer require full-length androgen receptor. Proc Natl Acad Sci. 2010;107(39):16759-16765. doi:10.1073/pnas.1012443107

24. Antonarakis ES, Lu C, Wang $\mathrm{H}$, et al. AR-V7 and resistance to enzalutamide and abiraterone in prostate cancer. $N$ Engl $\mathrm{J} \mathrm{Med}$. 2014;371(11):1028-1038. doi:10.1056/NEJMoa1315815 
25. Scher HI, Beer TM, Higano CS, et al. Antitumour activity of MDV3100 in castration-resistant prostate cancer: a Phase 1-2 study. Lancet. 2010;375(9724):1437-1446. doi:10.1016/S0140-6736(10) 60172-9

26. Scher HI, Fizazi K, Saad F, et al. Increased survival with enzalutamide in prostate cancer after chemotherapy. $N$ Engl J Med. 2012;367 (13):1187-1197. doi:10.1056/NEJMoa1207506

27. Beer TM, Armstrong AJ, Rathkopf DE, et al. Enzalutamide in metastatic prostate cancer before chemotherapy. $N$ Engl J Med. 2014;371 (5):424-433. doi:10.1056/NEJMoa1405095

28. Beer TM, Armstrong AJ, Rathkopf D, et al. Enzalutamide in men with chemotherapy-naïve metastatic castration-resistant prostate cancer: extended analysis of the phase 3 PREVAIL study. Eur Urol. 2017;71(2):151-154. doi:10.1016/j.eururo.2016.07.032

29. Sternberg CN, Fizazi K, Saad F, et al. Enzalutamide and survival in nonmetastatic, castration-resistant prostate cancer. $N$ Engl J Med. 2020;382(23):2197-2206. doi:10.1056/NEJMoa2003892

30. Tombal B, Saad F, Penson D, et al. Patient-reported outcomes following enzalutamide or placebo in men with non-metastatic, castration-resistant prostate cancer (PROSPER): a multicentre, randomised, double-blind, phase 3 trial. Lancet Oncol. 2019;20 (4):556-569. doi:10.1016/S1470-2045(18)30898-2

31. Smith MR, Saad F, Chowdhury S, et al. Apalutamide treatment and metastasis-free survival in prostate cancer. $N$ Engl J Med. 2018;378 (15):1408-1418. doi:10.1056/NEJMoa1715546

32. Fizazi K, Shore N, Tammela TL, et al. Darolutamide in nonmetastatic, castration-resistant prostate cancer. $N$ Engl J Med. 2019;380 (13):1235-1246. doi:10.1056/NEJMoa1815671

33. Group PC. Maximum androgen blockade in advanced prostate cancer: an overview of the randomised trials. Lancet. 2000;355 (9214):1491-1498. doi:10.1016/S0140-6736(00)02163-2

34. Gravis G, Fizazi K, Joly F, et al. Androgen-deprivation therapy alone or with docetaxel in non-castrate metastatic prostate cancer (GETUG-AFU 15): a randomised, open-label, phase 3 trial. Lancet Oncol. 2013;14(2):149-158. doi:10.1016/S1470-2045(12)70560-0

35. Smith MR, Saad F, Hussain M, et al. ARASENS: a phase 3 trial of darolutamide in combination with docetaxel for men with metastatic hormone-sensitive prostate cancer (mHSPC). J Clin Oncol. 2018;36 (6_suppl):TPS383-TPS383. doi:10.1200/JCO.2018.36.6_suppl. TPS383

36. Francini E, Yip S, Ahmed S, et al. Clinical outcomes of first-line abiraterone acetate or enzalutamide for metastatic castration-resistant prostate cancer after androgen deprivation therapy + docetaxel or ADT alone for metastatic hormone-sensitive prostate cancer. Clin Genitourin Cancer. 2018;16(2):130-134.

37. Maughan BL, Luber B, Nadal R, Antonarakis ES. Comparing sequencing of abiraterone and enzalutamide in men with metastatic castration-resistant prostate cancer: a retrospective study. Prostate. 2017;77(1):33-40. doi:10.1002/pros.23246

38. Terada N, Maughan BL, Akamatsu S, et al. Exploring the optimal sequence of abiraterone and enzalutamide in patients with chemotherapy-naïve castration-resistant prostate cancer: the Kyoto-Baltimore collaboration. Int J Urol. 2017;24(6):441-448. doi:10.1111/iju.13346

39. Khalaf DJ, Annala M, Taavitsainen S, et al. Optimal sequencing of enzalutamide and abiraterone acetate plus prednisone in metastatic castration-resistant prostate cancer: a multicentre, randomised, open-label, phase 2, crossover trial. Lancet Oncol. 2019;20 (12):1730-1739. doi:10.1016/S1470-2045(19)30688-6

40. Marchioni M, Di Nicola M, Primiceri G, et al. New antiandrogen compounds compared to docetaxel for metastatic hormone sensitive prostate cancer: results from a network meta-analysis. J Urol. 2020;203(4):751-759. doi:10.1097/JU.0000000000000636

41. Tucci M, Bertaglia V, Vignani F, et al. Addition of docetaxel to androgen deprivation therapy for patients with hormone-sensitive metastatic prostate cancer: a systematic review and meta-analysis. Eur Urol. 2016;69(4):563-573. doi:10.1016/j.eururo.2015.09.013
42. Rush HL, Cook AD, Brawley CD, et al. Comparative quality of life in patients randomized contemporaneously to docetaxel or abiraterone in the STAMPEDE trial. J Clin Oncol. 2020;38(6_suppl):14. doi:10.1200/JCO.2020.38.6_suppl.14

43. Sathianathen NJ, Alarid-Escudero F, Kuntz KM, et al. A cost-effectiveness analysis of systemic therapy for metastatic hormone-sensitive prostate cancer. Eur Urol Oncol. 2019;2 (6):649-655. doi:10.1016/j.euo.2019.01.004

44. Stockler MR, Martin AJ, Dhillon H, et al. Health-related quality of life in a randomized phase 3 trial of enzalutamide with standard first line therapy for mHSPC: ENZAMET, an ANZUP-led, international, co-operative group trial. Ann Oncol. 2019;30:v851-v934. doi:10.1093/annonc/mdz394.046

45. Williams S, Davis ID, Sweeney C, et al. Randomised phase 3 trial of enzalutamide in androgen deprivation therapy (ADT) with radiation therapy for high risk, clinically localized prostate cancer: ENZARAD (ANZUP 1303). Ann Oncol. 2018;36(6_suppl):TPS156-TPS156.

46. Lou DY, Fong L. Neoadjuvant therapy for localized prostate cancer: examining mechanism of action and efficacy within the tumor. Urol Oncol. 2016;34(4):182-192. doi:10.1016/j.urolonc.2013.12.001

47. McKay RR, Xie W, Lis R, et al. Results of a phase II trial of neoadjuvant abiraterone + prednisone + enzalutamide + leuprolide (APEL) versus enzalutamide + leuprolide (EL) for patients with high-risk localized prostate cancer (PC) undergoing radical prostatectomy (RP). J Clin Oncol. 2018;36(6_suppl):79. doi:10.1200/ JCO.2018.36.6_suppl.79

48. Efstathiou E, Davis JW, Titus MA, et al. Neoadjuvant enzalutamide (ENZA) and abiraterone acetate (AA) plus leuprolide acetate (LHRHa) versus AA+ LHRHa in localized high-risk prostate cancer (LHRPC). J Clin Oncol. 2016;34(15_suppl):5002. doi:10.1200/ JCO.2016.34.15_suppl.5002

49. Teo MY, Taplin M-E, Eastham JA, et al. Metacure: multi-arm multimodality therapy for very high risk localized and low volume metastatic prostatic adenocarcinoma. J Clin Oncol. 2019;37(7_suppl): TPS349. doi:10.1200/JCO.2019.37.7_suppl.TPS349

50. Taplin M-E, Gleave M, Evans CP, et al. PROTEUS: a randomized, double-blind, placebo (PBO)-controlled, phase 3 trial of apalutamide (APA) plus androgen deprivation therapy (ADT) versus PBO plus ADT prior to radical prostatectomy (RP) in patients with localized high-risk or locally advanced prostate cancer (PC). J Clin Oncol. 2019;37(15_suppl):TPS5100.

51. ICECaP Working Group. The development of intermediate clinical endpoints in cancer of the prostate (ICECaP). J Natl Cancer Inst. 2015;107(12):djv261.

52. Attard G, Borre M, Gurney H, et al. Abiraterone alone or in combination with enzalutamide in metastatic castration-resistant prostate cancer with rising prostate-specific antigen during enzalutamide treatment. J Clin Oncol. 2018;36(25):2639-2646. doi:10.1200/JCO.2018.77.9827

53. Morris MJ, Heller G, Bryce AH, et al. Alliance A031201: a phase III trial of enzalutamide (ENZ) versus enzalutamide, abiraterone, and prednisone (ENZ/AAP) for metastatic castration resistant prostate cancer (mCRPC).. J Clin Oncol. 2019;37(15_suppl):5008. doi:10.1200/JCO.2019.37.15_suppl.5008

54. Efstathiou E, Titus M, Wen S, et al. Enzalutamide in combination with abiraterone acetate in bone metastatic castration-resistant prostate cancer patients. Eur Urol Oncol. 2020;3(1):119-127.

55. Caffo O, Palesandro E, Nole F, et al. A multicentric phase II randomized trial of docetaxel (D) plus enzalutamide (E) versus docetaxel (D) as first-line chemotherapy for patients (pts) with metastatic castration-resistant prostate cancer (mCRPC): CHEIRON study. J Clin Oncol. 2019;37(7_suppl):148. doi:10.1200/JCO.2019.37.7_suppl.148

56. Smith MR, Goode M, Zietman AL, McGovern FJ, Lee H, Finkelstein JS. Bicalutamide monotherapy versus leuprolide monotherapy for prostate cancer: effects on bone mineral density and body composition. J Clin Oncol. 2004;22(13):2546-2553. doi:10.1200/ JCO.2004.01.174 
57. Iversen P, Tyrrell CJ, Kaisary AV, et al. Casodex (bicalutamide) $150-\mathrm{mg}$ monotherapy compared with castration in patients with previously untreated nonmetastatic prostate cancer: results from two multicenter randomized trials at a median follow-up of 4 years. Urology. 1998;51(3):389-396. doi:10.1016/S0090-4295(98)00004-1

58. Miller K, Mulders P, Freedland SJ, et al. EMBARK: a phase 3, randomized, efficacy and safety study of enzalutamide plus leuprolide, enzalutamide monotherapy and placebo plus leuprolide in men with high-risk nonmetastatic prostate cancer progressing after definitive therapy. Ann Oncol. 2016;27(suppl_6):vi264. doi:10.1093/ annonc/mdw372.53

59. Tombal B, Borre M, Rathenborg P, et al. Long-term antitumor activity and safety of enzalutamide monotherapy in hormone naïve prostate cancer: 3-year open label followup results. J Urol. 2018;199 (2):459-464. doi:10.1016/j.juro.2017.08.103

60. Tombal B, Borre M, Rathenborg P, et al. Long-term efficacy and safety of enzalutamide monotherapy in hormone-naïve prostate cancer: 1- and 2-year open-label follow-up results. Eur Urol. 2015;68 (5):787-794. doi:10.1016/j.eururo.2015.01.027

61. Tombal B, Borre M, Rathenborg P, et al. Enzalutamide monotherapy in hormone-naive prostate cancer: primary analysis of an open-label, single-arm, phase 2 study. Lancet Oncol. 2014;15(6):592-600. doi:10.1016/S1470-2045(14)70129-9

62. Zurth C, Sandman S, Trummel D, Seidel D, Nubbemeyer R, Gieschen H. Higher blood-brain barrier penetration of [14C]apalutamide and [14C]enzalutamide compared to [14C]darolutamide in rats using whole-body autoradiography. $J$ Clin Oncol. 2019;37 (7_suppl):156. doi:10.1200/JCO.2019.37.7_suppl.156

63. Ryan C, Wefel JS, Morgans AK. A review of prostate cancer treatment impact on the CNS and cognitive function. Prostate Cancer Prostatic Dis. 2019.

64. Fagerlund A, Cormio L, Palangi L, et al. Gynecomastia in patients with prostate cancer: a systematic review. PLoS One. 2015;10(8): e0136094. doi:10.1371/journal.pone.0136094

65. Fizazi K, Albiges L, Loriot Y, Massard C. ODM-201: a new-generation androgen receptor inhibitor in castration-resistant prostate cancer. Expert Rev Anticancer Ther. 2015;15 (9):1007-1017. doi:10.1586/14737140.2015.1081566

66. Fizazi K, Massard C, Bono P, et al. Safety and antitumour activity of ODM-201 (BAY-1841788) in castration-resistant, CYP17 inhibitornaïve prostate cancer: results from extended follow-up of the ARADES trial. Eur Urol Focus. 2017;3(6):606-614. doi:10.1016/j. euf.2017.01.010

67. Edwards J, Krishna NS, Grigor KM, Bartlett JMS. Androgen receptor gene amplification and protein expression in hormone refractory prostate cancer. Br J Cancer. 2003;89(3):552-556. doi:10.1038/sj. bjc. 6601127

68. Mostaghel EA, Zhang A, Hernandez S, et al. Contribution of adrenal glands to intratumor androgens and growth of castration-resistant prostate cancer. Clin Cancer Res. 2019;25(1):426-439. doi:10.1158/ 1078-0432.CCR-18-1431

69. Stanbrough M, Bubley GJ, Ross K, et al. Increased expression of genes converting adrenal androgens to testosterone in androgen-independent prostate cancer. Cancer Res. 2006;66 (5):2815-2825. doi:10.1158/0008-5472.CAN-05-4000

70. Taplin M-E, Bubley GJ, Shuster TD, et al. Mutation of the androgen-receptor gene in metastatic androgen-independent prostate cancer. $N$ Engl J Med. 1995;332(21):1393-1398.

71. Joseph JD, Lu N, Qian J, et al. A clinically relevant androgen receptor mutation confers resistance to second-generation antiandrogens enzalutamide and ARN-509. Cancer Discov. 2013;3 (9):1020-1029. doi:10.1158/2159-8290.CD-13-0226

72. Lallous N, Volik SV, Awrey S, et al. Functional analysis of androgen receptor mutations that confer anti-androgen resistance identified in circulating cell-free DNA from prostate cancer patients. Genome Biol. 2016;17(1). doi:10.1186/s13059-015-0864-1.
73. Hu R, Lu C, Mostaghel EA, et al. Distinct transcriptional programs mediated by the ligand-dependent full-length androgen receptor and its splice variants in castration-resistant prostate cancer. Cancer Res. 2012;72(14):3457-3462. doi:10.1158/0008-5472.CAN-11-3892

74. Tucci M, Zichi C, Buttigliero C, Vignani F, Scagliotti GV, Di Maio M. Enzalutamide-resistant castration-resistant prostate cancer: challenges and solutions. Onco Targets Ther. 2018;11:7353-7368. doi:10.2147/OTT.S153764

75. Teply BA, Wang H, Luber B, et al. Bipolar androgen therapy in men with metastatic castration-resistant prostate cancer after progression on enzalutamide: an open-label, phase 2, multicohort study. Lancet Oncol. 2018;19(1):76-86. doi:10.1016/S14702045(17)30906-3

76. Kregel S, Wang C, Han X, et al. Androgen receptor degraders overcome common resistance mechanisms developed during prostate cancer treatment. Neoplasia. 2020;22(2):111-119. doi:10.1016/j. neo.2019.12.003

77. Saito S, Fujimaki T, Panbangred W, Igarashi Y, Imoto M. Antarlides: a new type of androgen receptor (AR) antagonist that overcomes resistance to AR-targeted therapy. Angew Chem. 2016;55 (8):2728-2732. doi:10.1002/anie.201510079

78. Andersen RJ, Mawji NR, Wang J, et al. Regression of castrate-recurrent prostate cancer by a small-molecule inhibitor of the amino-terminus domain of the androgen receptor. Cancer Cell. 2010;17(6):535-546. doi:10.1016/j.ccr.2010.04.027

79. Yang YC, Banuelos CA, Mawji NR, et al. Targeting androgen receptor activation function-1 with EPI to overcome resistance mechanisms in castration-resistant prostate cancer. Clin Cancer Res. 2016;22 (17):4466-4477.

80. Obst JK, Wang J, Jian K, et al. Revealing metabolic liabilities of ralaniten to enhance novel androgen receptor targeted therapies. ACS Pharmacol Transl Sci. 2019;2(6):453-467. doi:10.1021/ acsptsci.9b00065

81. Zhou T, Xu W, Zhang W, et al. Preclinical profile and phase I clinical trial of a novel androgen receptor antagonist GT0918 in castration-resistant prostate cancer. Eur J Cancer. 2020;134:29-40. doi:10.1016/j.ejca.2020.04.013

82. Njar VCO, Brodie AMH. Discovery and development of galeterone (TOK-001 or VN/124-1) for the treatment of all stages of prostate cancer. $J$ Med Chem. 2015;58(5):2077-2087. doi:10.1021/ jm501239f

83. Tokai pharmaceuticals announces clinical update. Available from: http://www.businesswire.com/news/home/20160726005553/en/ Tokai-Pharmaceuticals-Announces. Accessed July 1, 2020.

84. Madan RA, Schmidt KT, Karzai F, et al. Phase 2 study of seviteronel (INO-464) in patients with metastatic castration-resistant prostate cancer after enzalutamide treatment. Clin Genitourin Cancer. 2020;18(4):258-267.e1. doi:10.1016/j.clgc.2019.11.002

85. Genentech's IPATential150 study evaluating ipatasertib in combination with abiraterone and prednisone/prednisolone met one of its coprimary endpoints. Available from: https://www.gene.com/media/ press-releases/14861/2020-06-18/genentechs-ipatential150-studyevaluatin. Accessed July 15, 2020.

86. Galvão DA, Taaffe DR, Spry N, Joseph D, Turner D, Newton RU. Reduced muscle strength and functional performance in men with prostate cancer undergoing androgen suppression: a comprehensive cross-sectional investigation. Prostate Cancer Prostatic Dis. 2009;12 (2):198-203. doi:10.1038/pcan.2008.51

87. Cheung AS, Zajac JD, Grossmann M. Muscle and bone effects of androgen deprivation therapy: current and emerging therapies. Endocr Relat Cancer. 2014;21(5):R371-R394. doi:10.1530/ERC14-0172

88. Gonzalez BD, Jim HSL, Small BJ. Changes in physical functioning and muscle strength in men receiving androgen deprivation therapy for prostate cancer: a controlled comparison. Support Care Cancer. 2016;24(5):2201-2207. doi:10.1007/s00520-015-3016-y 
89. Moe EL, Borsch C, Garg B, et al. Falls and frailty in prostate cancer survivors on androgen deprivation therapy. J Clin Oncol. 2016;34 (3_suppl):134. doi:10.1200/jco.2016.34.3_suppl.134

90. Das P, Simmonds K, Ali A, Mckenna L, Chakraborti PR. Effects of enzalutamide and abiraterone on patients physical, social and emotional function: result of a prospective patients reported outcome tool. J Clin Oncol. 2018;36(15_suppl):e18857. doi:10.1200/ JCO.2018.36.15_suppl.e18857

91. Wall BA, Galvão DA, Fatehee N, et al. Reduced cardiovascular capacity and resting metabolic rate in men with prostate cancer undergoing androgen deprivation: a comprehensive cross-sectional investigation. Adv Urol. 2015;2015:1-7. doi:10.1155/2015/976235
92. Harrison MR, Khouri M, Armstrong AJ, et al. PEAX: men with metastatic castrate-resistant prostate cancer (mCRPC) treated with either sipuleucel-T (SIP-T), enzalutamide (ENZA) or abiraterone acetate $(\mathrm{ABI})$ undergoing cardiopulmonary exercise testing (CPET). J Clin Oncol. 2019;37(7_suppl):281. doi:10.1200/ JCO.2019.37.7_suppl.281

93. Beer TM, Shore ND, Morgans AK, et al. DaroACT: darolutamide and enzalutamide effects on physical and neurocognitive function and daily activity in patients with castration-resistant prostate cancer (CRPC). J Clin Oncol. 2020;38(15 suppl):TPS5587-TPS5587. doi:10.1200/JCO.2020.38.15_suppl.TPS5587

\section{Publish your work in this journal}

OncoTargets and Therapy is an international, peer-reviewed, open access journal focusing on the pathological basis of all cancers, potential targets for therapy and treatment protocols employed to improve the management of cancer patients. The journal also focuses on the impact of management programs and new therapeutic

Submit your manuscript here: https://www.dovepress.com/oncotargets-and-therapy-journal agents and protocols on patient perspectives such as quality of life, adherence and satisfaction. The manuscript management system is completely online and includes a very quick and fair peer-review system, which is all easy to use. Visit http://www.dovepress.com/ testimonials.php to read real quotes from published authors.

submit your manuscript 